\title{
Predictive Value of Exercise Stress Testing in a Family Medicine Population
}

\author{
Robert J. Newman, MD, Mark Darrow, MD, Doyle M. Cummings, PharmD, \\ Valerie King, MD, MPH, Lauren Whetstone, PhD, Suzanne Kelly, MPH, and \\ Eric Jalonen, $B A$
}

Purpose: Exercise stress testing (EST) is a screening test for coronary artery disease. Previous studies from the cardiology literature show an overall sensitivity of $67 \%$ and specificity of $72 \%$ with variable predictive values depending on pretest probability. The purpose of the current study was to evaluate the predictive value of EST in a family medicine population in eastern North Carolina.

Methods: This is a retrospective case series of $339 \mathrm{EST}$ performed in a family medicine center from July 2001 to April 2005. EST results were classified as positive, negative, or equivocal. Outcomes studied from a review of outpatient and inpatient electronic medical record data and telephone follow-up included myocardial infarction, cardiac catheterization with angioplasty and stenting, coronary artery bypass grafting, a new diagnosis of coronary artery disease, and cardiac death. Mean duration of follow-up was 47 months, with a range of 27 to 72 months.

Results: Nearly all patients had low to intermediate risk pretest probability. Five tests were positive, 32 were equivocal, and 302 were negative. There were 2 false-positive tests, both in female patients. There were 2 false-negative tests, both of which were treated with good outcomes. Two of 32 equivocal results had cardiac outcomes. Considering equivocal tests as positive, the overall sensitivity in this series was $71.4 \%$; specificity was $\mathbf{9 0 . 4 \%}$. The positive predictive value was $13.5 \%$ and the negative predictive value was $99.3 \%$.

Conclusions: The high negative predictive value for EST in this outpatient family medicine population is noteworthy and reassuring. EST is a cost-effective strategy for triaging the common complaint of chest pain in low- to intermediate-risk patients in primary care practices and should be included in the services offered to family medicine patients. (J Am Board Fam Med 2008;21:531-8.)

Coronary artery disease (CAD) is the leading cause of death in the United States and accounted for 479,305 deaths in 2003 and nearly 1,200,000 myocardial infarctions per year. ${ }^{1}$ White men and African-Americans of both sexes have the highest incidence of CAD. Death rates have declined $26.5 \%$ from 1993 to 2003, primarily because of improved risk factor modification and better treatments.

Chest pain is the most common presenting complaint indicating $\mathrm{CAD}$ and is seen frequently by

This article was externally peer reviewed.

Submitted 20 November 2007; revised 3 March 2008; accepted 10 March 2008.

From the Department of Family Medicine (RJN), Brody School of Medicine, East Carolina University (DMC, LW, EJ), Greenville, NC; the Coastal Area Health Education Center (MD), Wilmington, NC; and Oregon Health and Science University (VK), Portland, OR.

Funding: none.

Conflict of interest: none declared.

Corresponding author: Robert J. Newman, MD, East Carolina University, Department of Family Medicine, Brody School of Medicine, 600 Moye Blvd, Greenville, North Carolina 27834 (E-mail: newmanr@ecu.edu). primary care physicians. Exercise stress testing (EST) is often used to decide which patients need further work-up and referral to a cardiologist. In 2005 , only $12.8 \%$ of family physicians were doing EST in their offices, up from $7.9 \%$ in $1990 .^{2,3}$ Family physicians in rural locations were more likely to offer this service than those in suburban locations. $^{4}$

There is a surprising paucity of studies about the use of EST by family physicians for the diagnosis of CAD, with only 3 small case series noted from 1979 to $1985 .^{5-7}$ Eberly ${ }^{5}$ in 1979 reported a series of 140 patients undergoing EST with high pretest probability. Thirty-seven percent had a positive EST and $14 \%$ had a false-negative test. This study was limited because outcomes were not prespecified. ${ }^{5}$ Zoller and Boyd ${ }^{6}$ reported on 275 cases in 1985; $22.5 \%$ had positive studies, $75.6 \%$ had negative studies, and $1.8 \%$ had equivocal results. Follow-up ranged from 1 month to 6 years. They reported a $9.3 \%$ false-positive rate and a $12.5 \%$ false-negative 
rate but did not report predictive values for the test. There were 2 complications involving persistent electrocardiographic (EKG) changes and hospitalization but both had good outcomes. ${ }^{6}$ Harmon $^{7}$ reported his series of 309 stress tests from South Carolina in 1988. Follow-up was from 1 to 5 years. There was correlative cardiac catheterization data in 56 patients $(18 \%)$, which was the only outcome studied. For patients with symptomatic chest pain there was a $26 \%$ false-positive rate $38 \%$ for women) and a $2 \%$ false-negative rate.

Many studies, including those cited above, have documented the safety of ESTs performed in the office by family physicians. Mead ${ }^{8}$ reported a series from Seattle in 1979 of 2490 tests without morbidity or mortality. Ilia and Gueron ${ }^{9}$ reported a series in 1997 of 24,153 tests performed by family physicians from a community practice in Israel with very low morbidity and no mortality. There are countless studies available in the cardiology literature on EST and its use in evaluating CAD, with a mean sensitivity of $67 \%$ and a mean specificity of $72 \% .{ }^{10}$

However, these cardiology studies have significant work-up and referral bias because they come from a specialty practice. Froelicher et al ${ }^{11,12}$ reported a series of 814 patients with chest pain from the Veteran's Administration System who underwent both EST and cardiac catheterization with limited work-up bias; they found a sensitivity of $45 \%$ and a specificity of $85 \%$ for EST. Morise and Diamond ${ }^{13}$ reported that the accuracy of EST for the diagnosis of CAD is lower in women than in men, and the difference is not explained by referral bias.

The predictive value of EST for diagnosing CAD depends heavily on pretest probability of CAD. One large study of 5103 patients reported positive predictive values (PPVs) of $21 \%, 62 \%$, and $92 \%$ in low, intermediate, and high pretest probability groups, respectively. Negative predictive values (NPVs) were $94 \%, 72 \%$, and $28 \%$ in the same low, intermediate, and high pretest probability groupings. ${ }^{14}$ Thus, NPV increases with lower pretest probability of disease whereas PPV decreases. This situation would be typical of a primary care population presenting for exercise testing without the referral bias seen in cardiology studies of EST. Another series of 1010 patients presenting to an emergency department, reported by Gibler, ${ }^{15}$ found EST in the chest pain unit to have a PPV of $44.4 \%$ and an NPV of $98.7 \%$.
The purpose of this study was to evaluate the predictive value of EST in a family medicine outpatient population in eastern North Carolina. There are no studies that report this in the family medicine literature and studies from cardiology are limited by referral and work-up bias, as noted above. In addition, our study evaluated well-defined, prespecified, patient-oriented outcomes, which was not consistently done in previous family medicine case series.

\section{Methods}

This is a retrospective case series of 339 patients in whom outpatient EST was performed in the Family Medicine Center at Brody School of Medicine at East Carolina University from July 2001 to April 2005. The cases were selected by searching billing records for CPT code 93015 and represented all patients who had an outpatient EST during this interval. The only exclusion criteria was known preexisting CAD (5 patients).

Three board-certified physician faculty who were trained during residency to do EST performed the tests. A Quinton model Q 55 treadmill (Cardiac Science Corp., Bothell, WA) was used with either the standard Bruce or modified Bruce protocol, the selection dependent on predicted exercise capacity. Patients were asked to exercise to their maximum capacity with the goal of reaching $85 \%$ of their maximum predicted heart rate. The study received approval from the Brody School of Medicine Institutional Review Board. All data sheets were kept without names or other identification to protect patient confidentiality. Medical records of these patients were reviewed and abstracted by a trained data specialist. Data collected on each patient included age; sex; ethnicity; indication for the test; risk factors for CAD; exercise time; percent of maximum predicted heart rate achieved; symptoms of angina (graded as $0=$ none, $1=$ mild, and $2=$ exercise limiting); Duke treadmill score (DTMS); baseline blood pressure; and blood pressure at peak exercise. The result of the test was recorded as negative, equivocal, or positive. Positive tests were defined as showing $\geq 1 \mathrm{~mm}$ of flat or down-sloping ST depression in any of the standard EKG leads. Equivocal tests were defined as not meeting the positive test criteria but showing concerning change (eg, symptoms of chest pain without EKG change of ischemia or inadequate 
exercise time or inability to achieve target heart rate). ST depression was interpreted by the Quinton Q 4500 treadmill computer system (Cardiac Science Corp.) with confirmation by the supervising physician (RJN and MD). A DTMS ${ }^{16}$ was calculated in each case as follows: DTMS $=$ time of exercise $-4 \mathrm{x}$ (Angina Index graded as 0 to 2 ) $-5 \mathrm{x}$ (mm of ST depression). The DTMS was then correlated with cardiac outcome. Any complications of the test were also recorded. All EST data were abstracted from a standard EST template routinely used in our electronic medical record system. Patients with equivocal or positive tests were referred to our cardiology group for exercise sestamibi study, adenosine sestamibi stress testing, or directly for cardiac catheterization.

Outcome data were obtained from careful review of the outpatient electronic medical record and the university hospital records on each patient. Two trained data specialists each independently reviewed these records for outcomes (EJ). Follow-up intervals ranged from a minimum of 27 months to a maximum of 72 months (mean duration, 47 months). Outcomes studied included documented myocardial infarction, cardiac catheterization with angioplasty and stenting, coronary artery bypass grafting (CABG), a new diagnosis of $\mathrm{CAD}$, and cardiac death. The university hospital is the primary site of hospitalization for all family medicine patients and provides all levels of cardiac care. To ensure complete outcome data capture, a phone follow-up survey was conducted in July and August 2007 by a trained technician (EJ). We were able to obtain phone follow-up data for $71 \%$ of patients.

Descriptive statistics were used to characterize the study population with respect to demographics, cardiac risk factors, test indications, and EST results. We then evaluated the relationship between EST results and any chart-documented cardiovascular outcomes by calculating sensitivity, specificity, PPV, NPV, and positive and negative likelihood ratios using standard formulas from a $2 \times 2$ table. ${ }^{17}$ Confidence intervals were also calculated for each of these values. DTMS was correlated with cardiac outcome.

\section{Results}

Patient demographics of the 339 patients are presented in Table 1. Fifty-two percent were men and
Table 1. Characteristics of the Exercise Stress Testing Study Population

\begin{tabular}{lc}
\hline Age (years) & \\
Mean (range) & $50.0(24-91)$ \\
SD & \pm 10.66 \\
Sex (\%) & \\
Men & 52 \\
Women & 48 \\
Race (\%) & \\
African-American & 52 \\
White & 45 \\
Other & 3 \\
Risk Factors (\% [n]) & \\
Hypertension & $59(201)$ \\
Hypercholesterolemia & $29(99)$ \\
Diabetes Mellitus & $23(78)$ \\
Smoker, previous or current & $21(70)$ \\
Family history of CAD & $8(27)$ \\
None reported & $20(69)$ \\
\hline
\end{tabular}

$\mathrm{CAD}$, coronary artery disease.

$48 \%$ were women. Forty-five percent of patients were white, $52 \%$ were African-American, and 3\% were other races. The age range was from 24 to 91 years with a mean age of 50 years.

The most common indications for EST were chest pain (59\%), preexercise evaluation (8\%), shortness of breath (4\%), multiple cardiac risk factors $(3.8 \%)$, and screening $(2.3 \%)$. No indications were listed in the EST template in $23 \%$ of patients. The study population had a significant number of cardiac risk factors, as noted in Table 1 . There were no risk factors reported in 69 patients $(20.1 \%)$.

Table 2 shows a standard $2 \times 2$ analysis of EST for the cardiac outcomes studied. For the purposes of this analysis, equivocal results were counted as positive results. There were a total of 5 positive studies, 2 of which were false-positives as demonstrated by subsequent radionuclide stress testing or cardiac catheterization. Both of the false-positive studies were in female patients. There were 32 equivocal studies, 2 of which subsequently showed a cardiac outcome. Two studies were false-negative tests with a high DTMS. Figure 1 summarizes the outcomes sorted by EST result.

A total of 7 patients, as summarized in Table 3 had outcomes of myocardial infarction, cardiac catheterization with angioplasty and stenting, CABG, or a new diagnosis of CAD. Three cases were true positives with a positive EST and an outcome event within 10 months of the test, all 


\begin{tabular}{|c|c|c|c|c|c|}
\hline \multirow[b]{2}{*}{ Treadmill Result } & \multicolumn{5}{|c|}{ Cardiac Outcomes $^{\dagger}$} \\
\hline & Yes & No & Total & Value & CI \\
\hline Positive $^{\ddagger}$ & 5 & 32 & 37 & & \\
\hline Negative & 2 & 300 & 302 & & \\
\hline Total & 7 & 332 & 339 & & \\
\hline Sensitivity & & & & 0.7143 & $0.3589-0.9178$ \\
\hline Specificity & & & & 0.9036 & $0.8671-0.9309$ \\
\hline PPV & & & & 0.1351 & $0.0591-0.2797$ \\
\hline NPV & & & & 0.9934 & $0.9762-0.9982$ \\
\hline Positive likelihood ratio & & & & 7.4110 & $4.1800-13.1400$ \\
\hline Negative likelihood ratio & & & & 0.3160 & $0.0980-1.0210$ \\
\hline Probability of disease & & & & 0.0260 & $0.0100-0.0419$ \\
\hline Overall accuracy & & & & 0.8997 & $0.8631-0.9286$ \\
\hline
\end{tabular}

*Calculations were based on formulas from http://faculty.vassar.edu/lowry/prop1.html. Formulas for confidence intervals from Newcome RG. Two sided confidence intervals for the single proportion; comparison of seven methods. Stat Med 1998;17:857-72. ${ }^{\dagger}$ Cardiac outcomes included myocardial infarction, cardiac catheterization with angioplasty and stenting, coronary artery bypass graft, new diagnosis of coronary artery disease, and cardiac death.

${ }^{\ddagger}$ Equivocal results are included as positive tests.

demonstrating CAD at the subsequent cardiac catheterization. One of these patients had a negative radionuclide stress test immediately after an EST performed in the office, but subsequently developed an acute myocardial infarction 10 months later. Catheterization showed 2-vessel CAD with stenting and a good outcome. Two patients with equivocal results had documented CAD at catheterization within 6 weeks of the EST. Of the 2 patients with false-negative results, one had a myocardial infarction within 2 months of the EST. Catheterization showed single-vessel disease, which was stented with excellent outcome. The other patient with a false-negative result had an initial negative test with DTMS of 13 in May 2004, then had a positive stress echo for new symptoms in October 2006. Catheterization in October 2006 showed multivessel disease and the patient underwent CABG with good outcome. All 7 cardiac outcomes were in male patients and occurred within 16 months of the EST. A total of 3 patients underwent CABG.

Six patients died over the follow-up period, none of cardiac causes. Causes of death included alcoholic cirrhosis, laryngeal cancer, gastric cancer, systemic sclerosis, Alzheimer's disease, and an adverse drug reaction to a psychotropic medication.

Applying standard formulas ${ }^{17}$ to the data in Table 2 yields a sensitivity of $71.4 \%$ and specificity of 90.4\% from the ESTs performed in this outpatient

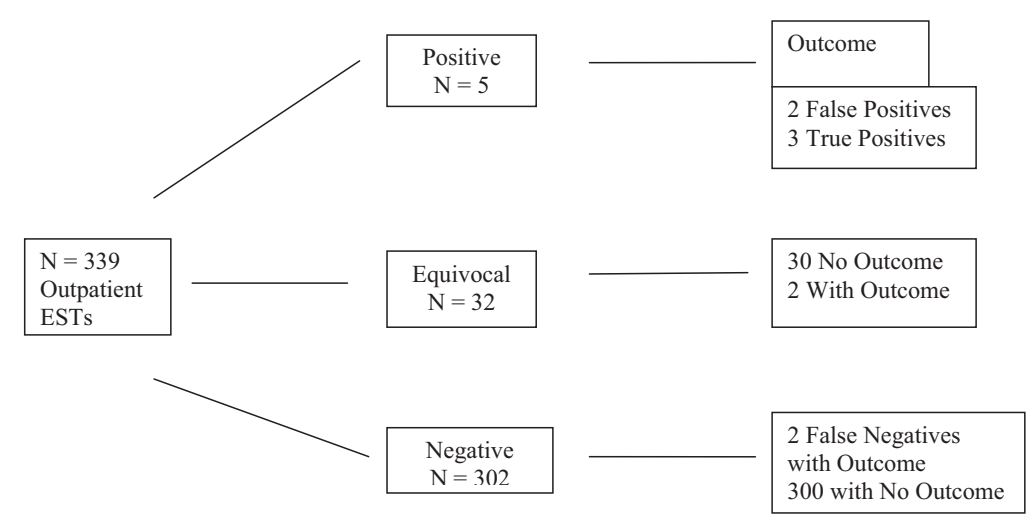

Figure 1. Summary of exercise stress testing results. 


\begin{tabular}{|c|c|c|c|c|c|c|}
\hline \multirow[b]{2}{*}{$\begin{array}{l}\text { Patient } \\
\text { Number }\end{array}$} & \multirow[b]{2}{*}{$\begin{array}{l}\text { EST } \\
\text { Result }\end{array}$} & \multirow[b]{2}{*}{ Cardiac Outcome } & \multirow[b]{2}{*}{ Time to Outcome } & \multicolumn{3}{|c|}{ Descriptive Data } \\
\hline & & & & $\begin{array}{l}\text { Age } \\
(\mathrm{yr})\end{array}$ & Race/Sex & Risk Factors \\
\hline 74 & Positive & $\begin{array}{l}\text { Acute MI; } \\
\text { catheterization; } \\
\text { stenting } 2 \text { vessels }\end{array}$ & 10 months & 65 & $\begin{array}{l}\text { African-American } \\
\text { male }\end{array}$ & $\begin{array}{l}\text { HTN, DM, } \\
\text { hypercholesterolemia }\end{array}$ \\
\hline 128 & Negative & $\begin{array}{l}\text { Acute } \mathrm{MI} \text {; } \\
\text { catheterization; } \\
\text { stenting single vessel }\end{array}$ & 2 months & 51 & $\begin{array}{l}\text { African-American } \\
\text { male }\end{array}$ & $\begin{array}{l}\text { HTN, smoker, } \\
\text { hypercholesterolemia }\end{array}$ \\
\hline 157 & Equivocal & $\begin{array}{l}\text { Catheterization; stenting } \\
2 \text { vessels; subsequent } \\
\text { CABG }\end{array}$ & 5 weeks & 57 & $\begin{array}{l}\text { African-American } \\
\text { male }\end{array}$ & $\begin{array}{l}\text { DM, HTN, } \\
\text { Hypercholesterolemia }\end{array}$ \\
\hline 176 & Positive & $\begin{array}{l}\text { Catheterization; stenting } \\
2 \text { vessels }\end{array}$ & 2 months & 42 & White male & FH, CAD, hypercholesterolemia \\
\hline 230 & Negative & $\begin{array}{l}\text { Catheterization; 3-vessel } \\
\text { CAD; CABG }\end{array}$ & 29 months & 49 & White male & $\begin{array}{l}\text { HTN, negative EST (May } \\
\text { 2004), positive stress echo } \\
\text { (October 2006) }\end{array}$ \\
\hline 271 & Equivocal & $\begin{array}{l}\text { Catheterization; stenting } \\
\text { single vessel }\end{array}$ & 5 weeks & 44 & White male & Smoker, HTN \\
\hline 298 & Positive & $\begin{array}{l}\text { Catheterization; 3-vessel } \\
\text { CAD; CABG }\end{array}$ & 1 week & 54 & White male & $\begin{array}{l}\text { HTN, DM, } \\
\text { hypercholesterolemia }\end{array}$ \\
\hline
\end{tabular}

EST, exercise stress test; MI, myocardial infarction; HTN, hypertension; DM, diabetes mellitus; CAD, coronary artery disease; CABG, coronary artery bypass graft.

family medicine population. The PPV was $13.5 \%$ for EST in our Family Medicine Center whereas NPV was $99.3 \%$. For our study, the positive likelihood ratio was 7.4 and negative likelihood ratio was 0.32 . Confidence intervals for these results are shown in Table 2.

DTMS was calculated for all ESTs performed in this series. The DTMS did correlate with the likelihood of having a cardiac outcome; thus, 3 of 56 patients $(5.4 \%)$ with a DTMS $\leq 5$ had a cardiac outcome. There were only 4 cardiac outcomes of 283 studies (1.4\%) in which the DTMS was $>5$.

There were no serious complications in this study. Two patients had hypotension after EST and 64 had minor arrhythmias (premature atrial contractions, premature ventricular contractions, and 1 case of atrial fibrillation) with good outcomes. There were no myocardial infarctions or deaths resulting from EST and no significant morbidity resulted from the test.

\section{Discussion}

The high NPV of EST for subsequent patientoriented cardiac outcomes in this outpatient family medicine population with low to intermediate pretest probability is very reassuring. The high NPV, relative to cardiology studies, probably re- flects the lower pretest probability in a family medicine population compared with a cardiology clinic population with referral bias. This study's strength is that it is one of the few from family medicine outpatient populations, and the only one to study predictive values of EST for patientoriented outcomes in this population of patients. Our study differs from other reported family medicine studies in that there were far fewer positive EST results. This result probably reflects our practice of admitting patients with high pretest probability when they presented with chest pain and studying these patients in the hospital. In addition, a decline in the incidence of CAD has occurred since these earlier studies. One limitation of our study is the variable follow-up times, which ranged from 27 to 72 months. It is also possible that some patients had a cardiac event in another location than those we sampled. However, our medical center is the only referral center for a large region and we verified our records review with telephone follow-up. Further research with data from multiple family medicine outpatient practices is needed to verify our findings.

A strong case can be made to include EST in the services offered to family medicine patients. There are many indications for EST in primary care practice, including evaluation of chest pain 
Table 4. Selection of Patients for Exercise Stress Testing in a Primary Care Setting

\begin{tabular}{ll}
\hline & $\begin{array}{c}\text { ACC/AHA } \\
\text { Class }\end{array}$ \\
\hline $\begin{array}{l}\text { 1. Symptomatic patients-adults with chest } \\
\text { pain with intermediate pretest probability } \\
\text { of CAD (see Table 5) }\end{array}$ & I \\
2. Generating an exercise prescription & \\
3. Determining functional capacity & \\
4. Evaluating antianginal therapy & \\
5. Evaluating patients after MI for risk & I \\
stratification & \\
6. Establishing severity and prognosis of CAD & I \\
- Duke Score assessment & \\
7. Evaluating dysrhythmias & I \\
8. Asymptomatic patients (limited indications) & II \\
A. Diabetics before starting moderate- to \\
high-intensity exercise and age >35 \\
years; type 2 DM for >10 years; type 1 \\
$\begin{array}{l}\text { DM for >15 years; presence of other } \\
\text { cardiac risk factors, microvascular } \\
\text { complications, or macrovascular } \\
\text { complications }\end{array}$ \\
$\begin{array}{l}\text { B. Men > } 45 \text { years old, women >55 years } \\
\text { old who plan to start a vigorous exercise } \\
\text { program; high-risk public safety } \\
\text { occupations; high risk for CAD with } \\
\text { multiple other CAD risk factors }\end{array}$ \\
\hline
\end{tabular}

Modified from refs. 10 and 28.

*This is the most common indication.

${ }^{\dagger}$ Some primary care physicians may choose to refer these patients with known CAD for exercise sestamibi study.

ACC/AHA, American College of Cardiology/American Heart Association ; CAD, coronary artery disease; MI, myocardial infarction; DM, diabetes mellitus.

and dyspnea, following the course and severity of $\mathrm{CAD}$, preexercise screening in patients with multiple cardiac risk factors, and determining functional capacity to write an exercise prescription. ${ }^{18,19}$
Table 4 is a suggested format for selecting patients for EST evaluation in a primary care setting. Table 5 shows the method of predicting pretest probability of CAD based on age, sex, and the description of chest pain. Guidelines from the American College of Cardiology and the American Heart Association recommend EST as a class I indication for the evaluation of the common clinical situation of adult patients with intermediate pretest probability of CAD. ${ }^{10}$ Table 6 lists suggested exclusion criteria for EST in a primary care setting and Table $7^{10}$ lists contraindications to the procedure. Consideration should be given to doing stress echocardiogram in women with higher pretest probabilities because this test has fewer false positives in women.

Standard techniques for performing EST have been well described, and these should be followed rigorously to ensure safety and standardization of the procedure. ${ }^{20}$ Appropriate training through residencies or courses such as those offered annually by the American Academy of Family Physicians should be undertaken with a period of proctoring or mentoring by a clinician experienced in performing ESTs.

The EST result can be classified as either positive, negative, equivocal, or indeterminate. ${ }^{21}$ As in this series, the majority of patients with a negative EST and good exercise time can be reassured, but should be instructed to report persistent symptoms and to continue risk factor modifications. One population-based study from Minnesota showed that longer exercise capacity on the treadmill was protective of cardiac events and mortality. ${ }^{22}$ Conversely, a recent study of 9191 patients referred for an EST showed that reduced exercise capacity was

Table 5. Pretest Probability of Coronary Artery Disease by Age, Gender, and Symptoms*

\begin{tabular}{llcccc}
\hline Age (years) & Gender & Typical Angina Pectoris & Atypical Chest Pain & Nonanginal Chest Pain & Asymptomatic \\
\hline \multirow{2}{*}{$30-39$} & Men & Intermediate & Intermediate & Low & Very low \\
& Women & Intermediate & Very low & Very low & Very low \\
$40-49$ & Men & High & Intermediate & Intermediate & Low \\
& Women & Intermediate & Low & Very low & Very low \\
$50-59$ & Men & High & Intermediate & Intermediate & Low \\
& Women & Intermediate & Intermediate & Low & VeryLow \\
$60-69$ & Men & High & Intermediate & Intermediate & Low \\
& Women & High & Intermediate & Intermediate & Low \\
\hline
\end{tabular}

Modified from refs. 10 and 28.

${ }^{*}$ High indicates $>90 \%$; intermediate, $10 \%$ to $90 \%$; low, $<10 \%$; very low, $<5 \%$. Intermediate pretest probability is an ACC/AHA Class I indication for exercise stress testing. 
Table 6. Suggested Exclusion Criteria for Exercise Stress Testing in a Primary Care Setting

1. Contraindications (see Table 7)

2. Patients who cannot walk $\geq 2$ flights of stairs or 2 city blocks; refer for adenosine or dobutamine sestamibi study

3. Patients with resting EKG abnormalities: right or left bundle branch block, ST segment depression at rest; refer for ESS

4. Women with high pretest probability (see Table 4); refer for stress echocardiography

5. Men with high pretest probability (see Table 4); refer for ESS

6. Patients on digoxin; refer for ESS

7. Patients with Wolf-Parkinson-White Syndrome; refer for ESS

8. Patients with paced rhythm; refer for ESS

9. In general, patients with known CAD should undergo ESS, although valuable information can be gained from exercise stress test

Modified from refs. 10 and 28.

EKG, electrocardiogram; ESS, exercise sestamibi study; CAD, coronary artery disease.

associated with increased risk for cardiovascular events. ${ }^{23}$ Patients with positive, equivocal, or indeterminate results should be referred for additional study. Patients with high pretest probability and a positive EST can be referred directly for cardiac catheterization. The DTMS can be used for risk stratification and to determine the urgency of cardiology referral, with those having a low score $(\leq 5)$ being referred for prompt evaluation. ${ }^{24}$

Cardiologists have moved away from using a standard EST to evaluate patients as more sophisticated and expensive tests with higher reimbursement have become available. ${ }^{25}$ The continued use of standard EST by primary care physicians to triage chest pain patients as described above has the potential to create tremendous health care cost savings. Specifically, at our institution the billing for a standard EST is \$483 compared with an exercise sestamibi study, which is billed at $\$ 3283$. This 7-fold increase in cost is hardly justified in the case of a low-risk patient with atypical chest pain who can be reassured safely with a negative EST. The following quote from Victor Froelicher, a cardiologist and noted authority on EST summarizes this nicely: "As George Bernard Shaw said 80 years ago, 'the doctor does the test he is paid (the most) for.' By attempting to decrease medical expenditures by targeting high frequency procedures, the EKG and standard exercise test have been devalued. Unfortunately, that drives practice to the more expensive modalities that increase in volume and cause even greater increases in health care costs. ${ }^{25}$

The above gives a strong case for including EST in the services offered by primary care physicians and has important implications for residency training. Estimates range from $31 \%$ to $50 \%$ of family medicine residencies are currently offering EST training. ${ }^{26,27}$ Only $12.8 \%$ of family physicians offer this procedure in their offices, and lack of training and the cost of the equipment were cited as the major barriers to performing ESTs. ${ }^{2}$ Residency programs in both family medicine and internal medicine should be encouraged to offer a competency-based curriculum for ESTs. By increasing the number of primary care physicians offering this procedure, maintaining quality of care with tremendous health care cost savings can be realized.

\section{Conclusion}

We have shown that EST can be safely and successfully performed in an outpatient family medicine setting in patients with low to intermediate pretest probability of disease. This study demonstrates high NPVs that are reassuring to both patients and providers and suggests that EST can be a cost-saving procedure in primary care.

\section{Table 7. Contraindications to Exercise Stress Testing}

Absolute

Acute myocardial infarction (within 2 days)

High-risk unstable angina

Uncontrolled cardiac arrhythmias

Symptomatic severe aortic stenosis

Uncontrolled symptomatic heart failure

Acute pulmonary embolus or pulmonary infarction

Acute myocarditis or pericarditis

Acute aortic dissection

Relative

Left main coronary stenosis

Moderate stenotic valvular heart disease

Electrolyte abnormalities

Severe arterial hypertension $(>200 / 110)$

Tachyarrhythmias or bradyarrhythmias

Hypertrophic cardiomyopathy and other forms of outflow tract obstruction

Mental or physical impairment leading to inability or willingness to exercise adequately

High-degree atrioventricular block

Modified from ref. 10. 
We would like to acknowledge the University of North Carolina Department of Family Medicine Faculty Development Fellowship Faculty; Trena Carmon, BS; and Brian Burkhart, MPH.

\section{References}

1. American Heart Association. Heart attack and angina statistics. Available at http://www.americanheart. org/presenter.jhtml?identifier $=4591$. Accessed 9 September 2008.

2. American Academy of Family Physicians. Practice Profile II survey. Performance of diagnostic procedures in family physicians practices. Available at http://www.aafp.org/online/en/home/aboutus/specialty/ facts/64.htm. Accessed 2007.

3. Jacobson S, Nuovo J. Exercise stress test training in family practice residency programs. J Am Board Fam Pract 1993;6:289-91.

4. Goeschel DP, Gilbert CS, Crabtree BF. Geographic variation in exercise testing by family physicians. $\mathrm{J}$ Fam Pract 1994;38:132-8.

5. Eberly AL. Exercise testing in family practice. J Fla Med Assoc 1980;67:845-7.

6. Zoller DP, Boyd GE. Six-year experience with graded exercise testing in a model family practice office. J Fam Pract 1985;21:451-4.

7. Harmon GE. Treadmill testing for the primary care physician. J S C Med Assoc 1988;84:398-400.

8. Mead WF. Maximal exercise testing-Bruce protocol. J Fam Pract 1979;9:479-90.

9. IIia R, Gueron M. Exercise stress testing in a community clinic: experience with 38,970 patients. Coron Artery Dis 1997;89:703-4.

10. Gibbons RJ, Balady GJ, Bricker JT, et al. ACC/AHA 2002 guideline update for exercise testing: summary article. A report of the American College of Cardiology/American Heart Association Task Force on Practice Guidelines (Committee to Update the 1997 Exercise Testing Guidelines). J Am Coll Cardiol 2002;40:1531-40.

11. Froelicher VF, Fearon W, Ferguson C, et al. Lessons learned from studies of the standard exercise ECG test. Chest 1999;116:1442-51.

12. Froelicher VF, Lehmann KG, Thomas R, et al. The electrocardiographic exercise test in a population with reduced workup bias: diagnostic performance, computerized interpretation, and multivariable prediction. Ann Intern Med 1998;128:965-74.

13. Morise AP, Diamond GA. Comparison of the sensitivity and specificity of exercise electrocardiography in biased and unbiased populations of men and women. Am Heart J 1995;130:741-7.

14. Morise AP. Are the American College of Cardiology/ American Heart Association guidelines for exercise testing for suspected coronary artery disease correct? Chest 2000;118:535-41.

15. Gibler BW, Runyon JP, Levy RC, et al. A rapid diagnostic and treatment center for patients with chest pain in the emergency department. Ann Emerg Med 1995;25:1-8.

16. Mark DB, Shaw L, Harrell FE Jr, et al. Prognostic value of a treadmill exercise score in outpatients with suspected coronary artery disease. N Engl J Med 1991;325:849-83.

17. Straus S, Richardson S, Glasziou P, Haynes B. Evidence-based medicine: How to practice and teach EBM. 3rd ed. Elsevier; 2005. p. 74.

18. Grauer K. Exercise stress test training. J Am Board Fam Pract 1993;6:524-5.

19. Mead WF. Is exercise tolerance testing indicated for diagnosis and/or screening in family practice? An affirmative view. J Fam Pract 1989;28:473-80.

20. Pina IL, Balady GJ, Hanson P, et al. Guidelines for clinical exercise testing laboratories: a statement for healthcare professionals from the Committee on Exercise and Cardiac Rehabilitation. American Heart Association. Circulation 1995;91:912-21.

21. Darrow M. Ordering and understanding the exercise stress test. Am Fam Physician. 1999;59:401-10.

22. Roger V, Jacobsen S, Pellikka P, et al. Prognostic value of treadmill exercise testing. Circulation 1998; 98:2836-41.

23. Peterson P, Magid D, Ross C, et al. Association of exercise capacity on treadmill with future cardiac events in patient referred for exercise testing. Arch Intern Med 2008;168:174-9.

24. Mark DB. Risk stratification in patients with chest pain. Prim Care 2001;28:99-118.

25. Froelicher V. Exercise testing in the new millennium. Prim Care 2001;28:1-4.

26. Jurica V, Baumgardner DJ, Lawrence SL. Graded exercise stress test training in family practice and internal medicine residencies. J Fam Pract 1989;29: 537-41.

27. Grauer K. Family physicians: exercise testing and community needs. J Fam Pract 1994;38:127-9.

28. Evans C. Clinical Procedures Workshop on Exercise Testing, Annual Scientific Assembly, American Academy of Family Physicians, 2003. 